\title{
Cloning, Expression, and Role in Pathogenicity of pg1 Encoding the Major Extracellular Endopolygalacturonase of the Vascular Wilt Pathogen Fusarium oxysporum
}

\author{
Antonio Di Pietro and M. Isabel G. Roncero \\ Departamento de Genética, Facultad de Ciencias, Universidad de Córdoba, 14071 Córdoba, Spain \\ Accepted 28 October 1997.
}

pg1 encoding the major in vitro extracellular endopolygalacturonase of the tomato vascular wilt pathogen $F u$ sarium oxysporum f. sp. lycopersici was cloned and sequenced. The deduced mature protein had a calculated molecular mass of $35.5 \mathrm{kDa}$ and a pI of 6.2, and showed significant similarity with other fungal endoPGs. pg1 mRNA was induced in vitro by citrus pectin, tomato vascular tissue, $0.1 \%$ D-galacturonic acid, and polygalacturonic acid, and repressed by $1 \%$ D-galacturonic acid and $1 \%$ glucose. Reverse transcription-polymerase chain reaction revealed pgl expression in roots and lower stems of tomato plants infected by $F$. oxysporum f. sp. lycopersici. Three naturally occurring $F$. oxysporum f. sp. melonis isolates deficient in PG1 were transformed with the cloned gene. The PG1 enzyme secreted by the transformants had the same molecular mass, pI, and glycosylation pattern as those of the donor isolate. Polygalacturonase activity in cultures of transformants grown in vitro on citrus pectin and on melon plants, but not on glucose, increased 10- to 20-fold, compared with the PG1-deficient wild-type isolate, whereas mycelial dry weight increased two- to threefold. Transformants exhibited the same degree of virulence toward susceptible muskmelon cultivars as the wildtype isolate and were avirulent on a resistant cultivar.

Endopolygalacturonases (endoPGs; poly- $\alpha$-1,4-galacturonide glycanohydrolase, EC 3.2.1.15) have long been proposed to play an important role in fungal pathogenicity to plants by depolymerizing homogalacturonan, a major component of the plant cell wall (Cooper 1984). Besides acting as virulence factors, endoPGs may also function as avirulence determinants through release of oligogalacturonide inducers of plant defense (Davis et al. 1984) and interaction with plant proteins that modulate PG activity (PGIPs) (Cervone et al. 1989). However, genetic evidence obtained by specific gene disruption in different plant pathogenic fungi so far does not support

Corresponding author: A. Di Pietro, Departamento de Genética, Facultad de Ciencias, Avda. de S. Alberto Magno S/N, 14071 Córdoba, Spain; Phone: 34-57218601; Fax 34-57218606; E-mail: ge2dipia@uco.es

Nucleotide sequence data are to be found at the EMBL and GenBank data bases under accession number U96456. an essential role of the major in vitro secreted endoPGs in pathogenicity (Gao et al. 1996; Scott-Craig et al. 1990).

The soilborne plant pathogen Fusarium oxysporum Schlechtend.:Fr. causes vascular wilt disease on a wide variety of crops (Beckman 1987). Previous studies have provided conflicting results on the involvement of endoPGs in the development of vascular wilt (Durrands and Cooper 1988; Howell 1976; Mann 1962). Recently, the major endoPG produced in vitro by $F$. oxysporum, PG1, has been purified and characterized, and evidence has been obtained for its presence in tomato plants infected by the pathogen (Di Pietro and Roncero 1996a). The present paper reports the cloning of the gene encoding PG1 of $F$. oxysporum f. sp. lycopersici and studies of its expression in vitro and during infection of tomato plants. Moreover, introduction of the gene into three PG1-deficient $F$. oxysporum f. sp. melonis isolates and the effect on in vitro saprophytic growth and on virulence toward muskmelon are described.

\section{RESULTS}

Isolation and characterization of $\mathrm{pg} 1$.

A genomic library of $F$. oxysporum f. sp. lycopersici isolate $42-87$ (race 2) was screened with the pCC 2 cDNA clone containing the endoPG gene from $F$. moniliforme (Caprari et al. 1993). Four recombinant phage clones were isolated and characterized by restriction and Southern hybridization analysis. Results indicated that the four clones encompassed different portions of the same genomic region. A 4.5-kb BamHI-PstI fragment and a $2.3-\mathrm{kb}$ HindIII fragment that hybridized to the $F$. moniliforme cDNA clone were subcloned in Bluescript $/ \mathrm{KS}^{+}$, and the sequence of both strands of the $2.3-\mathrm{kb}$ HindIII fragment containing the pgl gene and part of the $3^{\prime}$ flanking region was determined. The $p g l$ coding region consisted of an open reading frame of 1,110 bp encoding a 370 amino-acid polypeptide (Fig. 1). Four short introns were identified based on alignment with the sequence of the F. moniliforme endoPG gene and on conserved splice site consensus sequences of filamentous fungi. The nucleotide sequence of the $p g l$ coding region showed $87 \%$ identity to the $F$. moniliforme endoPG gene, whereas promoter and terminator regions showed less similarity. The $5^{\prime}$ flanking region of $p g l$ contained a putative TATA and CAAT box at positions -109 and -158 , respectively. As in $F$. moniliforme, no AATAAA se- 
quence typically preceding the polyadenylation site was found in the 3' flanking region. Several GATA motifs that constitute the recognition sequence of major nitrogen regulatory proteins (Kulmburg et al. 1993) were found at positions $-704,-648$, and -259 .

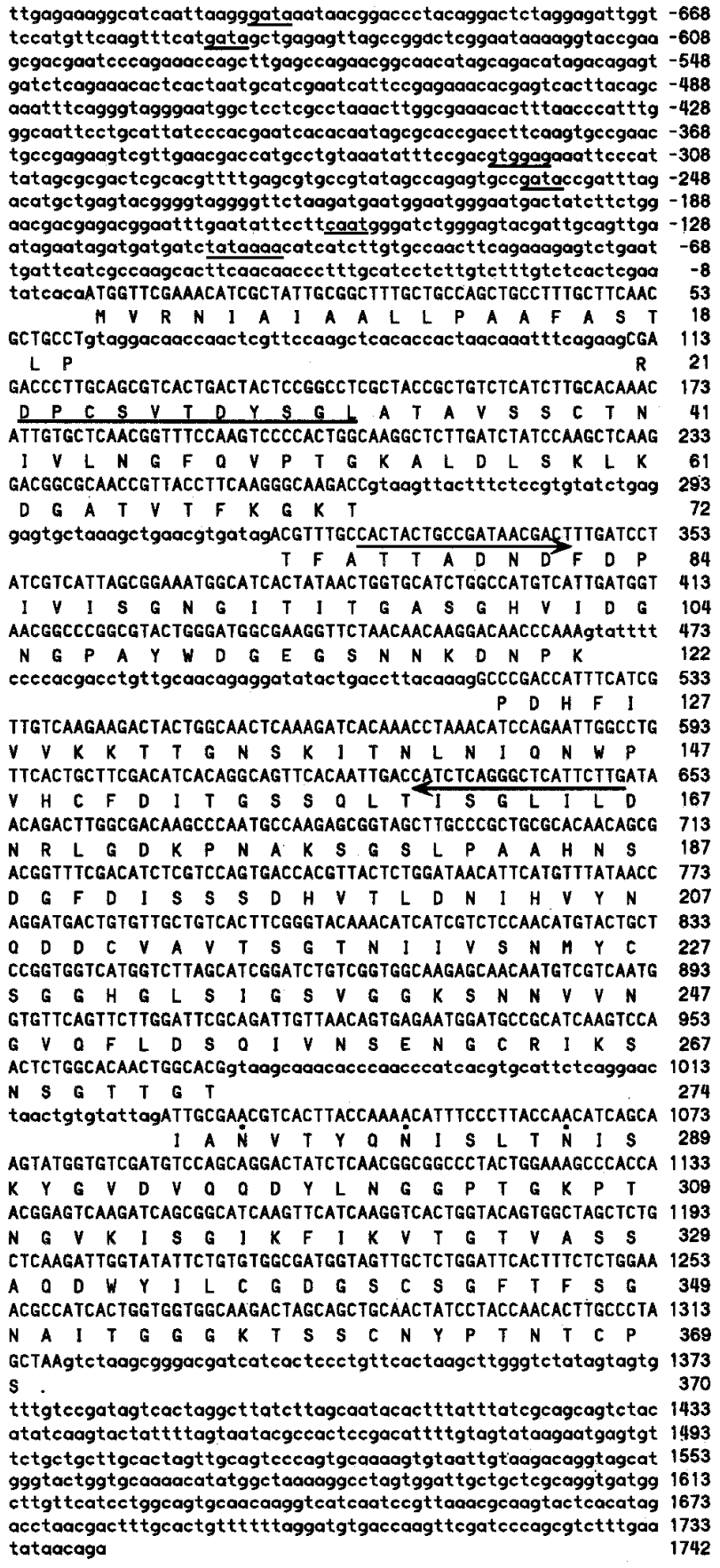

Fig. 1. Nucleotide sequence of the Fusarium oxysporum f. sp. lycopersici pgl gene. Introns are indicated in lowercase within the coding region. The putative TATA and CAAT box, as well as putative GATA elements and a CREA binding site, are underlined. Deduced amino acid sequence is shown below the nucleotide sequence. Underlined region represents the peptide sequence of the $\mathrm{N}$ terminus of the mature protein as obtained from amino acid sequencing. Putative N-glycosylation sites are marked with asterisk. Position and orientation of primers used for reverse transcription-polymerase chain reaction are shown by arrows.
Comparison of the predicted $p g l$ amino acid sequence with the N-terminal amino acid sequence of the mature PG1 enzyme revealed the presence of a 21-amino-acid, N-terminal signal peptide (von Heijne 1986). Molecular mass and pI calculations based on the predicted amino acid sequence fell within the range determined for the purified mature PG1 protein: $35.5 \mathrm{kDa}$ versus $35 \mathrm{kDa}$, determined by sodium dodecyl sulfate-polyacrylamide gel electrophoresis (SDS-PAGE), and a pI of 6.2 versus 7.0 of the main PG1 isoform, determined by analytical isoelectric focusing. The discrepancy in pI between the deduced and the determined values is probably due to $\mathrm{N}$ glycosylation of the enzyme (Di Pietro and Roncero 1996a). The deduced amino acid sequence of $p g 1$ showed $87 \%$ identity with the $F$. moniliforme endoPG and 45 to $49 \%$ identity with endoPGs of other plant-pathogenic fungi. As expected, identity was greatest at the putative catalytic domain between amino acid residues 232 and 243. EndoPGs of the two Fusarium spp. contained regions that diverged considerably from domains highly conserved among other fungal endoPGs, e.g., those between amino acids 79 and 84, 117 and 121, 127 and 133, 274 and 277, 293 and 296, and 365 and 370. The region between amino acids 174 and 181 was characteristic of the two Fusarium spp. since it was absent in all other fungal endoPGs. The most significant differences between $F$. oxysporum and the $F$. moniliforme endoPG were observed in the signal peptide and at some of the putative N-glycosylation sites.

The copy number of $p g 1$ was determined by Southern blot analysis of genomic DNA of $F$. oxysporum f. sp. lycopersici digested with six different restriction enzymes. A single hybridizing band was observed in all digests, consistent with the presence of a single copy of $p g l$ in the genome of $F$. oxysporum f. sp. lycopersici (data not shown).

\section{Expression of $p g 1$ in vitro and in infected tomato plants.}

In vitro expression of $p g l$ was determined by Northern (RNA) hybridization analysis of total RNA obtained from mycelia of $F$. oxysporum f. sp. lycopersici grown for $8 \mathrm{~h}$ in synthetic medium supplemented with different carbon sources. A single $1.3-\mathrm{kb} \mathrm{pgl}$ transcript was strongly induced on $1 \%$ citrus pectin and $2.5 \%$ tomato vascular tissue, and weakly on $1 \%$ sodium polygalacturonate (PGA) (Fig. 2). The monomer D-galacturonic acid (GA) induced pgl transcription at a concentration of $0.1 \%$ but repressed it at $1 \%$. No transcript was detected in mycelia grown either on $1 \%$ glucose or on $1 \%$ citrus pectin $+1 \%$ glucose. In the absence of any carbon source, extremely low levels of $p g l$ transcript were detected (results not shown).

To determine whether $p g l$ is expressed by $F$. oxysporum $\mathrm{f}$. sp. lycopersici during infection of its host plant, tomato seedlings were inoculated with microconidia of the pathogen and planted in minipots containing sterile vermiculite. Reverse transcription-polymerase chain reaction (RT-PCR) with genespecific primers was used to detect the presence of pgl transcript in roots and lower stems at different times after infection. As a positive control, RT-PCR was performed on total RNA isolated from mycelium grown for $8 \mathrm{~h}$ on citrus pectin, whereas total genomic DNA of $F$. oxysporum was used as a template for PCR reaction to compare the size of the amplified fragments with or without the intron $(325$ and $275 \mathrm{bp}$, respectively). Electrophoretic analysis of the RT-PCR products 
from infected roots showed a fragment of the expected size that was absent in the uninoculated controls (Fig. 3). Expression of pgl in roots was detected at all sampled time points, from 3 to 18 days after inoculation. In lower stems, no band of the expected size was found 3 days after inoculation whereas, after 8,12 , and 18 days, the 275-bp fragment corresponding to pgl cDNA was detected. Cloning and sequencing of the amplified band confirmed that the sequence completely matched that of the genomic clone except for the absence of the third intron. Moreover, Southern analysis of the amplified bands showed that only the 275-bp fragment hybridized with the pgl gene. This indicates that the higher molecular weight bands (300, 350, and $400 \mathrm{bp}$ ) found in PCR reaction of stem extracts were due to unspecific amplification, probably of plant DNA, as they were also found in the uninoculated controls.

\section{Transformation of PG1-deficient isolates} of $F$. oxysporum f. sp. melonis with $\mathrm{pg} 1$.

To investigate the role of $p g l$ in pathogenicity and saprophytic growth, the gene was transferred into three naturally occurring, PG1-deficient isolates of F. oxysporum f. sp. melonis that had been identified previously. Isolate $18 \mathrm{M}$ carries a pg1 allele disrupted by a 3.2-kb insertion, isolate A34 exhibits strongly reduced expression of $p g 1$, and isolate 275 lacks the pgl gene (A. Di Pietro, F. I. García-Maceira, M. D. HuertasGonzález, M. C. Ruíz-Roldan, Z. Caracuel, A. S. Barbieri, and M. I. G. Roncero, unpublished results). Transformation vector ppg 1-1 was constructed by cloning a 4.5-kb ApaI-SacI fragment containing the complete $p g 1$ promoter and coding region into pANblue 3 bearing the hygromycin $\mathrm{B}$ resistance

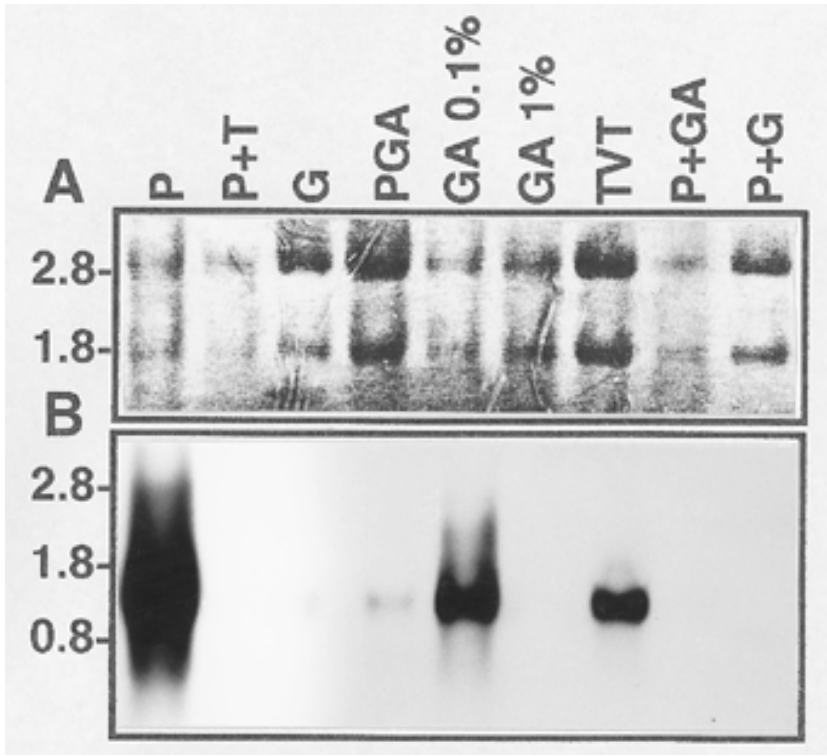

Fig. 2. Northern (RNA) hybridization analysis of $p g 1$ transcript accumulation in Fusarium oxysporum $\mathrm{f}$. sp. lycopersici mycelium grown for $8 \mathrm{~h}$ in synthetic medium containing the following carbon sources: P, $1 \%$ citrus pectin; $\mathrm{P}+\mathrm{T}, 1 \%$ pectin + tunicamycin; $\mathrm{G}, 1 \%$ glucose: $\mathrm{PGA}, 1 \%$ polygalacturonic acid, sodium salt; GA0.1, 0.1\% D-galacturonic acid; GA1, $1 \%$ D-galacturonic acid; TVT, $2.5 \%$ tomato vascular tissue; P+GA, $1 \%$ pectin $+1 \%$ D-galacturonic acid; $\mathrm{P}+\mathrm{G}, 1 \%$ pectin $+1 \%$ glucose. A, Total RNA blotted onto Nylon membrane and stained with $0.02 \%$ methylene blue. B, The filter shown in $\mathbf{A}$ was destained and hybridized with a digoxigenin-dUTP-labeled, 735-bp, internal polymerase chain reaction fragment of $p g 1$. Molecular size markers are indicated to the left. gene under control of the Aspergillus nidulans gpd promoter. As a negative control, vector ppgl-2 was constructed by cloning a 735-bp PCR fragment corresponding to nucleotides 114 to 849 of $p g l$ into pANblue3. Both constructs were used to transform PG1-deficient isolate $18 \mathrm{M}$ to hygromycin $\mathrm{B}$ resistance. Three out of $>100$ hygromycin-resistant ppg1-1 transformants (CO5, CO7, CO12) and one out of >100 ppgl-2 transformants $(\mathrm{CO} 4)$ were chosen at random, purified through two consecutive rounds of single-spore isolation, and used for further studies. PG1-deficient isolates A34 and 275 were transformed with ppg1-1, and two out of $>100$ hygromycinresistant transformants of each isolate $(\mathrm{CO} 8, \mathrm{CO} 9$ and $\mathrm{CO} 10$, CO11, respectively) were obtained as described above.

For Southern hybridization analysis of the transformants and wild-type isolates, genomic DNA was digested with HindIII and probed with the 735-bp internal PCR fragment of pgl (Fig. 4). In 18M, the presence of identical hybridizing

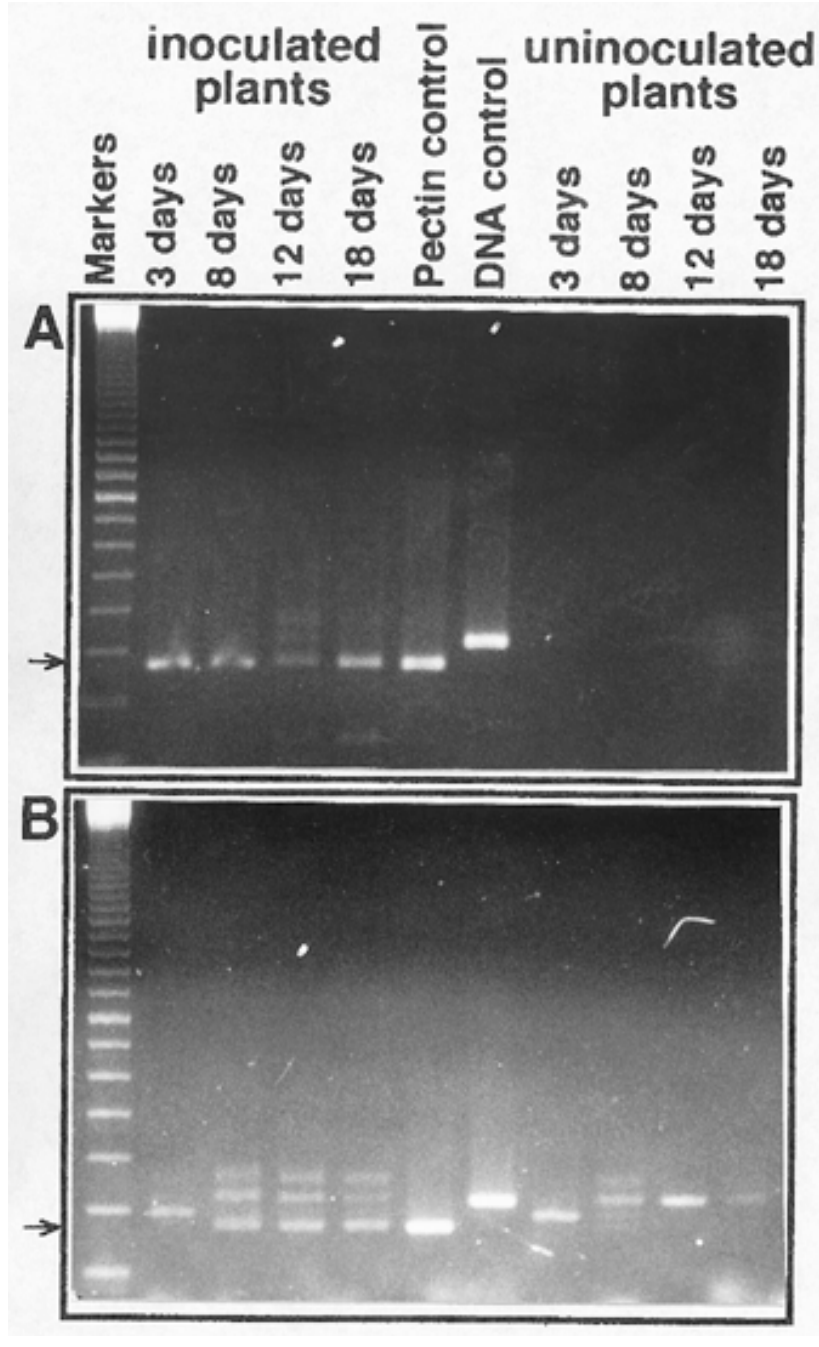

Fig. 3. Reverse transcription-polymerase chain reaction (RT-PCR) products showing expression pattern of $p g l$ during infection of tomato plants by Fusarium oxysporum f. sp. lycopersici. First-strand cDNAs generated from total RNA isolated at indicated time points from roots (A) and stems (B) of infected or uninfected plants were used as templates for PCR with primers specific for $p g 1$ (see Materials and Methods). Aliquots of PCR products were run on a $2 \%$ agarose gel with a 100-bp ladder marker. Position of the 275-bp pgl fragment is indicated by arrows. 
HindIII fragments $(1.7$ and $0.7 \mathrm{~kb})$ in the untransformed isolate and in all transformants was consistent with ectopic integration of the introduced constructs. Transformants $\mathrm{CO} 7$ and CO5 contained one and two additional copies, respectively, of ppg1-1 whereas CO12 carried multiple copies. CO4 apparently contained several copies of ppgl-2, possibly arranged in tandem. Integrative transformation was confirmed by Southern analysis of undigested DNA (data not shown). Southern hybridization analysis of HindIII-digested DNA of the transformants $\mathrm{CO} 8$ to $\mathrm{CO} 11$ and the corresponding untransformed isolates A34 and 275 suggested integration of one or multiple copies of ppg1-1 into the genome of the transformants (Fig. 4). The untransformed isolates showed either a high molecular weight band comigrating with undigested genomic DNA (A34) or no band (275) hybridizing to $p g l$.

Expression of the $p g 1$ gene in transformants and in the corresponding wild-type isolates was analyzed by Northern hybridization analysis of total RNA from mycelia grown for $12 \mathrm{~h}$ on citrus pectin. A transcript of the expected size was detected in $\mathrm{CO} 12$ and $\mathrm{CO} 7$ transformed with a complete copy of pgl, but not in $\mathrm{CO} 4$ transformed with an internal fragment of the gene and in the untransformed isolate $18 \mathrm{M}$ (data not shown). Isolate $\mathrm{CO} 12$ carrying multiple copies of $\mathrm{pg} 1$ showed a higher amount of transcript than the single-copy transformant $\mathrm{CO} 7$. A faint hybridizing band of $4.5 \mathrm{~kb}$ was detected in isolates $18 \mathrm{M}$ and $\mathrm{CO} 4$ that may correspond to the transcript of the $p g 1$ allele with the $3.2-\mathrm{kb}$ insertion. Similarly, no $\mathrm{pgl}$ transcripts were detected in isolates A34 and 275 whereas the corresponding transformants $\mathrm{CO} 8, \mathrm{CO} 9, \mathrm{CO} 10$, and $\mathrm{CO} 11$ produced a transcript of the expected size.

\section{PG activity and saprophytic growth of transformants.}

When grown on PGA agar, F. oxysporum f. sp. lycopersici isolate 42-87 produced a clear halo whereas $18 \mathrm{M}$ produced no halo (results not shown). Transformants $\mathrm{CO} 5$ and $\mathrm{CO} 12$ produced halos of different sizes, the larger halo of multicopy transformant $\mathrm{CO} 12$ correlating to the higher $p g 1$ mRNA level in this transformant. The results indicated that, in these isolates, halo production on PGA agar was mainly due to secre-

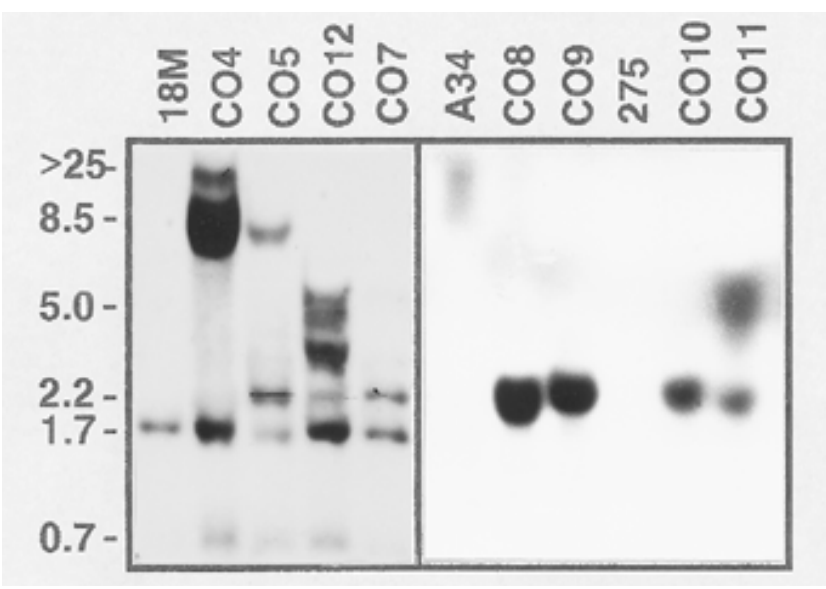

Fig. 4. Southern hybridization analysis of PG1-deficient Fusarium oxysporum f. sp. melonis isolates and different transformants. Genomic DNA was digested with HindIII and hybridized with a digoxigenindUTP-labeled, 735-bp, internal polymerase chain reaction fragment of pgl. Hybridizing bands sizes in $\mathrm{kb}$ are indicated to the left; 0.7-kb band in lane $18 \mathrm{M}$ is only faintly visible. tion of PG1. Concentrated culture filtrates of the different isolates and transformants grown for $24 \mathrm{~h}$ in liquid synthetic medium containing citrus pectin were analyzed by zymograms of isoelectric focusing gels and SDS-PAGE. The two characteristic PG activity bands with $\mathrm{pI}$ around 7.0, corresponding to differentially glycosylated isoforms of PG1 (Di Pietro and Roncero 1996a), were detected in the filtrate of the $F$. oxysporum $\mathrm{f}$. sp. lycopersici isolate $42-87$, but not in those of the three PG1-deficient melonis isolates (Fig. 5A). The different transformants secreted two activity bands with the same $\mathrm{pI}$ as those of isolate 42-87. SDS-PAGE and silver staining revealed two main protein bands corresponding to differentially glycosylated isoforms of PG1 in isolate $42-87$ and transformants $\mathrm{CO} 5, \mathrm{CO} 12$, and $\mathrm{CO} 7$, but not in the untransformed isolate $18 \mathrm{M}$ and in isolate $\mathrm{CO} 4$ transformed with an internal $\mathrm{pg} 1$ fragment (Fig. 5B). These data indicate that the PG1 protein was processed and secreted by the transformants in the same way as in the original isolate $42-87$.

In order to determine the contribution of $\mathrm{pg} 1$ to total extracellular PG activity and to saprophytic growth, isolates $F$. oxysporum f. sp. lycopersici $42-87$ and $F$. oxysporum f. sp. melonis $18 \mathrm{M}$, as well as transformants $\mathrm{CO} 5$ and $\mathrm{CO} 12$, were grown in liquid synthetic medium containing either citrus pectin, glucose, or entire melon plantlets as the sole carbon source. After $48 \mathrm{~h}$ of growth, total PG activity in the culture filtrate and the increase in mycelial dry weight were determined (Fig. 6). On citrus pectin, isolates 42-87, CO5, and $\mathrm{CO} 12$ secreted high levels of PG activity whereas the filtrate of $18 \mathrm{M}$ contained low PG activity (Fig. 6B). Multicopy transformant $\mathrm{CO} 12$ produced the highest extracellular PG activity (a more than 20-fold increase, compared with 18M). Higher

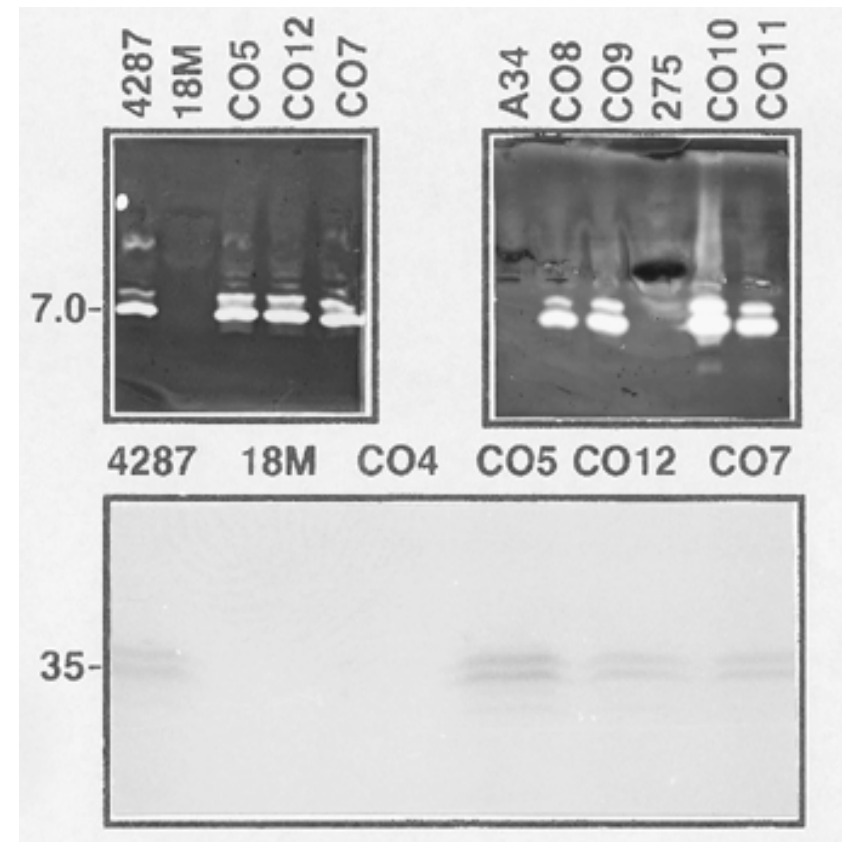

Fig. 5. Analytical isoelectric focusing zymograms (upper panels), and sodium dodecyl sulfate-polyacrylamide gel electrophoresis (SDSPAGE) and silver staining (lower panels) of concentrated and dialyzed culture filtrates of different Fusarium oxysporum isolates and transformants grown for $24 \mathrm{~h}$ in liquid synthetic medium with $1 \%$ (wt/vol) citrus pectin. $\mathrm{pI}$ and molecular weight of the main activity and protein bands, respectively, are shown to the left. 
levels of secreted PG activity correlated with an enhanced mycelial growth of the isolates. A twofold increase in mycelial dry weight was observed in 42-87, CO5, and CO12, compared with $18 \mathrm{M}$ (Fig. 6A). No difference between the isolates was found in glucose-grown cultures: PG activity was low in all filtrates and increases in mycelial dry weights were comparable. On melon plantlets, low PG activity and mycelial growth of $18 \mathrm{M}$ and high PG activity and increased mycelial growth of transformants CO5 and CO12 were detected. Surprisingly, $F$. oxysporum f. sp. lycopersici isolate $42-87$ secreted very low levels of PG activity during growth on melon plantlets, although mycelial growth of the isolate was comparable to that of $\mathrm{CO} 5$ and $\mathrm{CO} 12$. This was in contrast to results obtained on pectin .

Pectinolytic isozymes present in the filtrates of melongrown cultures were analyzed by zymograms of isoelectric focusing gels. PG1 activity bands were only detected in filtrates of $F$. oxysporum $\mathrm{f}$. sp. melonis transformant $\mathrm{CO} 5$, but not in isolate $18 \mathrm{M}$ and in $F$. oxysporum $\mathrm{f}$. sp. lycopersici isolate 42-87 (data not shown). In addition to PG1, another activity band with pI 9.0 corresponding to pectate lyase (Di Pietro and Roncero 1996c) was detected in isolates $18 \mathrm{M}$ and CO5, but not in 42-87.

\section{Virulence of pg1 transformants.}

Virulence of PG1-deficient $F$. oxysporum f. sp. melonis isolates and their respective PG1-producing transformants was determined against the muskmelon cultivar Amarillo Canario

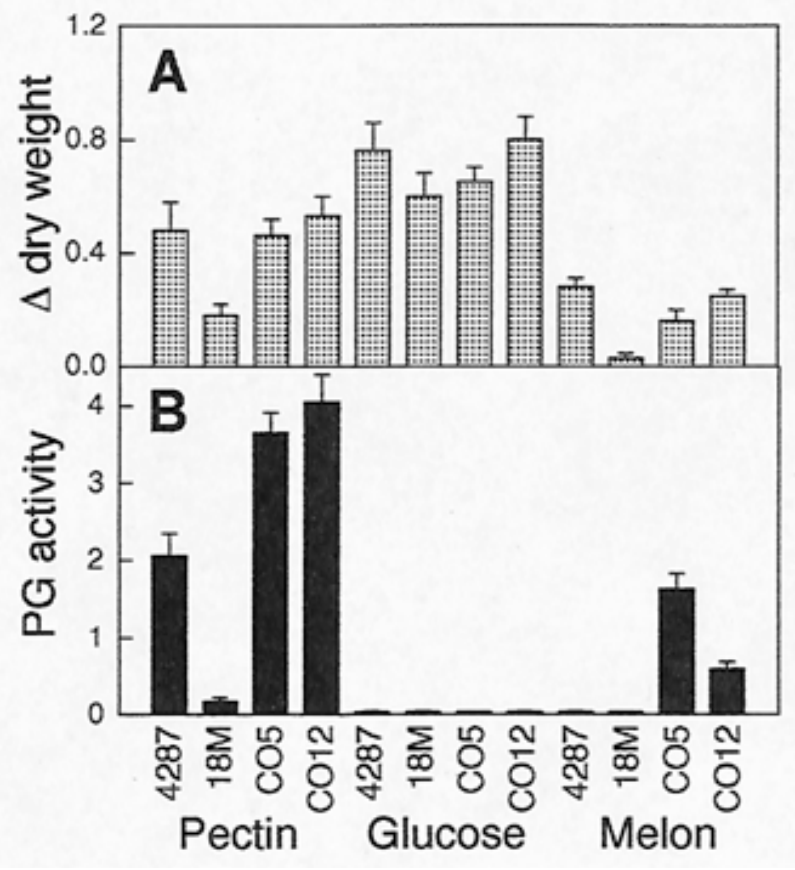

Fig. 6. A, Increase in mycelial dry weight (in g) of different Fusarium oxysporum isolates and transformants grown for $48 \mathrm{~h}$ in liquid synthetic medium with $1 \%(\mathrm{wt} / \mathrm{vol})$ citrus pectin, $1 \%$ (wt/vol) glucose, or $5 \%$ (wt/vol) melon plantlets as the sole carbon source. B, Total polygalacturonase activities (in nkatal $\mathrm{ml}^{-1}$ ) in dialyzed culture filtrates of different $F$. oxysporum strains and transformants grown under the above conditions, as determined by a reducing sugar assay (see Materials and Methods). Results are the means of two independent experiments. Standard deviations are indicated. susceptible to all races of the pathogen. The three wild-type isolates differed markedly in their degree of virulence. Isolate $18 \mathrm{M}$ (race 1) was highly virulent, killing the plants 10 days after inoculation, A34 (race 0) was less virulent, exhibiting both reduced and delayed disease symptoms, and 275 (race $1,2 \mathrm{w}$ ) showed an even lower level of virulence (Fig. 7). The transformants analyzed showed no difference in virulence, compared with the respective untransformed isolates: CO5 and $\mathrm{CO} 12$ had the same high level of virulence as $18 \mathrm{M}$, whereas $\mathrm{CO} 8$ and $\mathrm{CO} 10$ exhibited low virulence, as did the corresponding wild-type isolates A34 and 275, respectively. Isolate $18 \mathrm{M}$ and transformants $\mathrm{CO} 5$ and $\mathrm{CO} 12$ were also inoculated on muskmelon cvs. Pancha and Gustal, susceptible and resistant, respectively, to $F$. oxysporum f. sp. melonis race 1. Again, no difference in the virulence pattern was observed between the untransformed isolate and the PG1-producing transformants: all were equally virulent on cv. Pancha and avirulent on cv. Gustal (data not shown).

\section{DISCUSSION}

It has been suggested previously that endoPG may play a role in vascular wilt caused by $F$. oxysporum in at least two important phases of the disease: (i) during penetration of the different layers of the root cortex in order to reach the vascular system; and (ii) during colonization of the host by spreading upward through the xylem vessels (Beckman 1987). An endoPG (PG1) and an endoPL from $F$. oxysporum $\mathrm{f}$. sp. lycopersici have been detected in infected tomato plants, indicating a possible role of these enzymes in pathogenicity (Di Pietro and Roncero 1996a). In the present work, the $p g l$ gene was cloned by screening of a genomic library with an endoPG gene from F. moniliforme. Comparison of nucleotide and deduced amino acid sequences confirmed the high identity between the endoPG genes of the two Fusarium spp. Similarity was also ob-

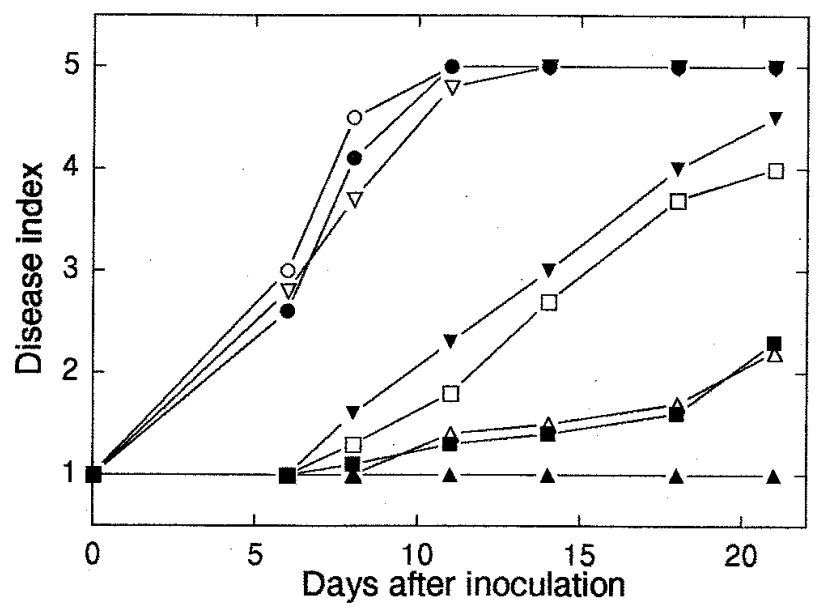

Fig. 7. Incidence of Fusarium wilt caused by different Fusarium oxysporum $\mathrm{f}$. sp. melonis isolates and transformants on plants of muskmelon cv. Amarillo Canario. Severity of disease symptoms was recorded at different times after inoculation, using an index ranging from 1 (healthy plant) to 5 (dead plant). Symbols indicate isolates/transformants: $18 \mathrm{M}$, solid circle; CO5, open circle; CO12, open inverted triangle; A34, solid inverted triangle; CO8, open square; 275, open triangle; CO10, solid square; and the uninoculated control, solid triangle. Values are means of two independent experiments, with five plants for each treatment. 
served with other fungal endoPGs, although some diverging regions, particularly that between amino acids 174 and 181, indicate that Fusarium spp. endoPGs may be regarded as a subgroup within fungal endoPGs. $p g l$ was present as a single copy in the genome of $F$. oxysporum as reported for endoPGs in F. moniliforme (Caprari et al. 1993), Cochliobolus carbonum (Scott-Craig et al. 1990), and Cryphonectria parasitica (Gao et al. 1996).

Similar to other fungal endoPG genes, $p g l$ was substrate induced and glucose repressed. The difference in $p g l$-inducing capacity between citrus pectin and PGA, observed previously in zymograms of the PG1 enzyme (Di Pietro and Roncero 1996a), is noteworthy since the PG1 enzyme acts well both on citrus pectin and PGA. Differential induction could be due to differences in $\mathrm{pH}$ of the culture media (3.5 with citrus pectin, 5.5 with PGA). It has been suggested previously that activation of endoPG genes functions via generation and uptake of small molecular weight degradation products. The monomer GA induced pgl expression at a concentration of $0.1 \%$ but not at $1 \%$, indicating a dual role, both as inducer and catabolite repressor. Glucose catabolite repression has been reported for most of the fungal endoPG genes and was suggested to be mediated by CREA (Reymond-Cotton et al. 1996). pgl was also repressed by glucose, and one putative CREA binding site (GTGGAG) (Kulmburg et al. 1993) was detected at position -322 in the pgl promoter region. The fact that only extremely low levels of transcript were detected in the absence of any carbon source indicates that $p g l$ is not induced by carbon starvation. Since $p g l$ of F. oxysporum f. sp. lycopersici is the first endoPG gene isolated from a vascular wilt pathogen, its expression during pathogenesis was of interest. RT-PCR suggested that $p g l$ was expressed throughout the entire disease cycle of $F$. oxysporum f. sp. $l y$ copersici, from penetration of the root through colonization of the vascular bundles to expression of the characteristic wilt symptoms. However, RT-PCR provides no information on the amount of $p g 1$ expression.

In order to assess the role of PG1 in pathogenicity of $F$. oxysporum, the encoding gene must be either disrupted in a PG1producing isolate or newly introduced into a PG1-deficient isolate. Targeted disruption of $p g l$ in F. oxysporum f. sp. lycopersici has so far failed due to ectopic integration of the disruption vector (A. Di Pietro and M. I. G. Roncero, unpublished results). However, the identification of three $F$. oxysporum f. sp. melonis isolates deficient in PG1 production allowed testing the importance of the enzyme in pathogenesis by transformation with a functional copy of the $p g l$ gene and subsequent analysis of the effect on virulence. The gene was expressed correctly in the different transformants as deduced from the presence of a transcript of the expected size in pectin-grown mycelia. The secreted PG1 protein was enzymatically active and apparently had the same molecular mass, pI, and glycosylation pattern as the enzyme from the original $F$. oxysporum f. sp. lycopersici isolate. This indicates that the PG1-deficient isolates contained all the cellular machinery necessary for correct expression and processing of the $p g 1$ gene and its product, respectively.

PG1-producing transformants exhibited the same degree of virulence toward muskmelon cultivars as the respective untransformed isolates, suggesting that PG1 is not essential for pathogenicity of $F$. oxysporum f. sp. melonis. Since $F$. oxysporum produces at least two PGs other than PG1 (Di Pietro and Roncero 1996b; Garcia-Maceira et al. 1997) and one pectate lyase (Di Pietro and Roncero 1996c), it cannot be excluded that the loss of one particular pectinolytic isozyme could be compensated by others, even if they may not share identical modes of action. In the present work, an additional pectinolytic activity other than PG1, caused by an endoPL, was secreted by the PG1-deficient isolate and the transformant during in vitro growth on melon plants. The same activity band has also been detected in roots of tomato plants infected by $F$. oxysporum f. sp. lycopersici (Di Pietro and Roncero 1996a), suggesting that endoPL may functionally complement endoPG during pathogenesis.

Most interest in cell wall-degrading enzymes of plant pathogens has focused on their role in infection and symptom expression on the host plant (Walton 1994). Besides the parasitic phase, life cycles of many facultative pathogens also contain saprophytic phases during which the microorganism must either proliferate and disperse or persist for extended time periods until it encounters a new host. When $F$. oxysporum enters the saprophytic phase, it moves from a protected situation within the host vascular tissue facing little competition, to the hostile and competitive environment of the soil (Beckman 1987). Even if $F$. oxysporum usually persists in the form of heavily walled chlamydospores, it must periodically undergo a recycling process on organic matter, mostly root material, in order to survive extended time periods in the absence of its host (Schippers and van Eck 1981). It may be during this saprophytic phase, and not during infection of the host plant, that cell wall-degrading enzymes are mostly required. Low levels of secreted pectinolytic activity in planta may be sufficient or even desirable for the pathogen due to the possible role of these enzymes as avirulence factors (Cervone et al. 1989; Davis et al. 1984). Thus, largely biotrophic parasites such as the rye pathogen Claviceps purpurea only secrete extremely low PG activities, both in planta and in axenic culture (Tenberge et al. 1996). However, in the saprophytic phase rapid secretion of large amounts of the appropriate lytic enzyme is likely to confer an advantage to facultative pathogens in competing with specialized saprophytes for nutrients. In fact, PG1-producing transformants of $F$. oxysporum f. sp. melonis were more competitive than PG1-deficient isolates during saprophytic growth on pectic substrates, as indicated by a higher production of fungal biomass. Whether this translates into an increase of in vivo ecological fitness as plant pathogens remains to be demonstrated.

\section{MATERIALS AND METHODS}

\section{Fungal isolates and culture conditions.}

F. oxysporum f. sp. lycopersici isolate $42-87$ (race 2) and $F$. oxysporum f. sp. melonis isolate $18 \mathrm{M}$ (race 1) were obtained from J. Tello, I.N.I.A., Madrid, and F. oxysporum f. sp. melonis isolates A34 and 275 were obtained from T. R. Gordon, University of California, Berkeley, and J. Gomez, C.I.D.A., Almería, Spain, respectively. Fungal isolates were stored as microconidial suspensions in $30 \%$ glycerol at $-80^{\circ} \mathrm{C}$. For extraction of DNA, mycelium was obtained from cultures grown for 4 days in potato dextrose broth (PDB; Difco, Detroit, MI) in Erlenmeyer flasks on a rotary shaker at $150 \mathrm{rpm}$ (TR-125, Infors AG, Bottmingen, Switzerland) and $28^{\circ} \mathrm{C}$. For analysis of gene expression and pectinolytic enzyme production, mi- 
croconidia obtained from 4-day-old PDB cultures were germinated for $12 \mathrm{~h}$ in fresh PDB medium. Germlings were washed twice in sterile water and transferred to synthetic medium (Di Pietro and Roncero 1996a) supplemented with $1 \%$ (wt/vol) of the appropriate carbon source (except for tomato vascular tissue and muskmelon plants, for which 2.5 and $5 \%$ [wt/vol] were added, respectively). Tunicamycin (Sigma Chemical, Madrid) was added to a final concentration of $75 \mu \mathrm{g} / \mathrm{ml}$. PGA, GA, and pectin from citrus fruits were from Sigma. Tomato vascular tissue obtained as previously described (Di Pietro and Roncero 1996c) or entire 20-day-old muskmelon plantlets, cv. Pancha, were added to the medium before autoclaving. Seeds of tomato and muskmelon cultivars used in the study were kindly provided by Sluis and Groot Ltd., El Parador, Almería, Spain.

\section{Isolation and characterization of $p g 1$.}

A lambda EMBL3 genomic library of $F$. oxysporum $\mathrm{f}$. sp. lycopersici strain 42-87 was screened with the $1.27-\mathrm{kb}$ pCC2 cDNA clone of the $F$. moniliforme endoPG gene as a probe (Caprari et al. 1993). Library screening, subcloning, and other routine procedures were performed as described in standard protocols (Sambrook et al. 1989). Sequencing of both strands of nested deletion clones was performed with the Dyedeoxy Terminator Cycle Sequencing Kit (Perkin Elmer, Foster City, CA) on an ABI Prism 310 Genetic Analyzer apparatus (Applied Biosystems, Foster City, CA). Analyses of sequencing data were carried out with the Wisconsin Package, Version 8.3 (Genetics Computer Group, Madison, WI) and the Lasergene Programs (DNAStar, Madison, WI).

\section{Nucleic acid isolation and analysis.}

Genomic DNA was extracted from $F$. oxysporum mycelium as described previously (Raeder and Broda 1985). DNA was digested with appropriate restriction enzymes and subjected to Southern hybridization analysis as described in standard protocols (Sambrook et al. 1989), using the non-isotopic digoxigenin labeling kit (Boehringer Mannheim, Mannheim, Germany) according to the instructions of the manufacturer. Total RNA was prepared as described (Chomczynski and Sacchi 1987). Five micrograms of total RNA was separated on a formaldehyde-1\% agarose gel and transferred to positively charged Nylon membranes (Boehringer Mannheim) by capillary transfer. For quantification, transferred RNA was stained on the membrane for $5 \mathrm{~min}$ in $0.02 \%$ methylene blue in $0.3 \mathrm{M}$ sodium acetate, $\mathrm{pH}$ 5.2. After destaining in $20 \%$ ethanol, filters were subjected to Northern hybridization analysis with the non-isotopic digoxigenin labeling kit. A single-stranded antisense DNA probe of a 735-bp PCR fragment corresponding to nucleotides 114 to 849 of $p g l$ was generated by a standard protocol (Konat et al. 1994).

\section{RT-PCR in infected tomato plants.}

Ten-day-old tomato seedlings (cv. Moneymaker) were inoculated with $F$. oxysporum f. sp. lycopersici strain $42-87$ by dipping the roots for $30 \mathrm{~min}$ in a suspension containing $5 \times$ $10^{6}$ microconidia per $\mathrm{ml}$ of water. Control plants were immersed in water. Seedlings were planted in minipots containing vermiculite and grown in a growth chamber at $25^{\circ} \mathrm{C}$ with $14 \mathrm{~h}$ light and $10 \mathrm{~h}$ dark. Three, 8, 12, and 18 days after inoculation, five plants from each treatment were removed and washed carefully under running water to remove adhering vermiculite particles. Roots and lower parts of the stems were separated with a sterile scalpel and frozen at $-80^{\circ} \mathrm{C}$. Total RNA was isolated from the tissue as described above. RTPCR was performed essentially following the protocol of Tenberge et al. (1996), using gene-specific primers flanking the third intron of $p g l$. One microgram of total RNA was treated with RNase-free DNAse (Boehringer Mannheim) and reversetranscribed into cDNA with murine leukemia virus reverse transcriptase (Gibco BRL, Paisley, UK) with the specific antisense primer 5'-CAA GAA TGA GCC CTG AGA TG-3'. The entire RT reaction was used for PCR amplification on a Perkin Elmer GeneAmp System 2400, with the sense primer 5'-CAC TAC TGC CGA TAA CGA CT-3' and the antisense primer described above. PCR conditions were as follows: denaturation at $94^{\circ} \mathrm{C}$ for $45 \mathrm{~s}$, annealing at $55^{\circ} \mathrm{C}$ for $35 \mathrm{~s}$, and extension at $72^{\circ} \mathrm{C}$ for $1 \mathrm{~min}$. An initial denaturation step of $2 \mathrm{~min}$ at $94^{\circ} \mathrm{C}$ and a final elongation step at $72^{\circ} \mathrm{C}$ for 6 min were performed. Aliquots of the PCR products were analyzed on $2 \%$ agarose gels. The amplified fragments were cloned into pGEM-T (Promega, Madison, WI) and sequenced in order to confirm their identity. For Southern analysis, amplified fragments were hybridized with the 735-bp pgl fragment described above.

\section{Construction of plasmids and fungal transformation.}

Plasmid ppg1-1 was constructed by subcloning a $4.5-\mathrm{kb}$ ApaI/SacI fragment of $F$. oxysporum f. sp. lycopersici DNA containing the $p g l$ promoter and coding region from Bluescript/KS ${ }^{+}$into pAN7blue3 (Bowyer et al. 1995), a modified pAN7-1 vector carrying the hygromycin B resistance gene under control of the Aspergillus nidulans gpd promoter (Punt et al. 1987). Plasmid ppg1-2 was constructed by subcloning a 735-bp PCR fragment corresponding to nucleotides 114 to 849 of $p g l$ into pAN7blue3.

Protoplasts of $F$. oxysporum were produced essentially as described (Powell and Kistler 1990), except for the use of $10 \%$ (wt/vol) Glucanex (Novo Ferment, Basel, Switzerland) for digestion of cell walls. The transformation protocol followed that of Malardier et al. (1989) with the addition of aurintricarboxylic acid to a final concentration of $10 \mathrm{mM}$. Five micrograms of transforming DNA was used for $2 \times 10^{7}$ protoplasts. After transformation, protoplasts were spread onto minimal medium and overlaid after $12 \mathrm{~h}$ with $66 \mu \mathrm{g}$ of hygromycin per $\mathrm{ml}$ (final concentration). Transformants appeared after 5 days and were transferred to hygromycin B plates and subjected to two consecutive rounds of single-spore isolation before being stored as microconidial suspensions at $-80^{\circ} \mathrm{C}$

\section{PGA plate assay, mycelial growth assay, PG enzyme assay, zymograms, and SDS-PAGE.}

PG production was analyzed in a plate assay on solid PGA medium, as described previously (Scott-Craig et al. 1990). For determination of fungal biomass, mycelium was obtained by filtration of liquid cultures through Whatman 3MM paper and lyophilized. Increase in biomass was calculated as the difference between mycelial dry weight at times 0 and $48 \mathrm{~h}$ of growth on the corresponding carbon source. For analysis of PG production, dialyzed and concentrated filtrates from fungal cultures were obtained, and total PG activity was determined by measuring the release of reducing groups from PGA by the 
method of Nelson-Somogyi as described previously (Di Pietro and Roncero 1996a). Appropriate controls without either enzyme or substrate were run simultaneously. The quantity of reducing sugar released was calculated from standards of GA. Enzyme activity was expressed in nanokatal (nkatal), defined as the amount of enzyme that releases $1 \mathrm{nmol}$ of D-galacturonic acid equivalent per s under the above conditions. For zymograms, pectinolytic activity was detected in IEF gels $(\mathrm{pH}$ 3-9), using a substrate overlay technique (Ried and Collmer 1985). SDS-PAGE was conducted in $11 \%$ (wt/vol) discontinuous acrylamide gels in a Mini Protean apparatus (BioRad, Madrid), followed by staining with $\mathrm{AgNO}_{3}$.

\section{Pathogenicity assays on muskmelon.}

Ten-day-old muskmelon seedlings in the first true leaf stage (cv. Amarillo Canario, susceptible to all $F$. oxysporum f. sp. melonis races, cv. Pancha, susceptible to race 1, and cv. Gustal, resistant to race 1 ) were inoculated with $F$. oxysporum f. sp. melonis isolates by dipping the roots for $30 \mathrm{~min}$ in a suspension containing $10^{6}$ microconidia per $\mathrm{ml}$ of water. Control plants were immersed in sterile water. Five seedlings per treatment were planted in minipots containing vermiculite and maintained in a growth chamber at $25^{\circ} \mathrm{C}$ with $14 \mathrm{~h}$ light and $10 \mathrm{~h}$ dark. At different times after inoculation, severity of disease symptoms was recorded, using an index from 1 (healthy plant) to 5 (dead plant). All experiments were performed twice.

\section{ACKNOWLEDGMENTS}

This research was supported by grants of the Comisión Interministerial de Ciencia y Tecnología (CICYT, Grants BIO93-0923-CO2-01 and BIO961139) and the European Commission (HCM-CT93-0244). A. D. P. was supported by a postdoctoral fellowship from the European Commission (HCM-CT93-0244). We gratefully acknowledge F. Cervone and G. De Lorenzo, Università "La Sapienza," Rome, for providing the F. moniliforme endoPG cDNA clone; M. Ruiz-Rubio, Universidad de Córdoba, for construction of the F. oxysporum genomic library; P. Bowyer, Sainsbury Laboratory, Norwich, UK, for providing the vector pAN7blue3; and I. Huedo, Universidad de Córdoba, for photographic work.

\section{LITERATURE CITED}

Beckman, C. H. 1987. The Nature of Wilt Diseases of Plants. American Phytopathological Society, St. Paul, MN.

Bowyer, P., Clarke, B. R., Lunness, P., Daniels, M. J., and Osbourn, A. E. 1995. Host range of a plant pathogenic fungus determined by a saponin detoxifying enzyme. Science 267:371-374.

Caprari, C., Richter, A., Bergmann, C., Lo Cicero, S., Salvi, G., Cervone, F., and De Lorenzo, G. 1993. Cloning and characterization of a gene encoding the endopolygalacturonase of Fusarium moniliforme. Mycol. Res. 97:497-505.

Cervone, F., Hahn, M. G., De Lorenzo, G., Darvill, A., and Albersheim, P. 1989. Host-pathogen interactions. XXXIII. A plant protein converts a fungal pathogenesis factor into an elicitor of plant defense responses. Plant Physiol. 90:542-548.

Chomczynski, P., and Sacchi, N. 1987. Single-step method of RNA isolation by acid guanidinium thiocyanate-phenol-chloroform extraction. Anal. Biochem. 162:156.

Cooper, R. M. 1984. The role of cell wall-degrading enzymes in infection and damage. Pages 13-27 in: Plant Diseases: Infection, Damage and Loss. R. K. S. Wood and G. J. Jellis, eds. Blackwell Scientific Publications, Oxford, UK.

Davis, K. R., Lyon, G. D., Darvill, A. G., and Albersheim, P. 1984. Hostpathogen interactions. XXV. Endopolygalacturonic acid lyase from Erwinia carotovora elicits phytoalexin accumulation by releasing plant cell wall fragments. Plant Physiol. 74:52-60.

Di Pietro, A., and Roncero, M. I. G. 1996a. Endopolygalacturonase from
Fusarium oxysporum f. sp. lycopersici: Purification, characterization, and production during infection of tomato plants. Phytopathology 86: 1324-1330.

Di Pietro, A., and Roncero, M. I. G. 1996b. Purification and characterization of an exo-polygalacturonase from the tomato vascular wilt pathogen Fusarium oxysporum f.sp. lycopersici. FEMS Microbiol. Lett. 145:295-299.

Di Pietro, A., and Roncero, M. I. G. 1996c. Purification and characterization of a pectate lyase from Fusarium oxysporum f.sp. lycopersici produced on tomato vascular tissue. Physiol. Mol. Plant Pathol. 49: $177-185$.

Durrands, P. K., and Cooper, R. M. 1988. The role of pectinases in vascular wilt disease as determined by defined mutants of Verticillium albo-atrum. Physiol. Mol. Plant Pathol. 32:363-371.

Gao, S., Choi, G. H., Shain, L., and Nuss, D. L. 1996. Cloning and targeted disruption of enpg-1, encoding the major in vitro extracellular endopolygalacturonase of the chestnut blight fungus, Cryphonectria parasitica. Appl. Environ. Microbiol. 62:1984-1990.

Garcia-Maceira, F. I., Di Pietro, A., and Roncero, M. I. G. 1997. Purification and characterization of a novel exopolygalacturonase from Fusarium oxysporum f.sp. lycopersici. FEMS Microbiol. Lett. 154:3743.

Howell, C. R. 1976. Use of enzyme-deficient mutants of Verticillium dahliae to assess the importance of pectolytic enzymes in symptom expression of Verticillium wilt of cotton. Physiol. Plant Pathol. 9:279-283.

Konat, G. W., Laszkiewicz, I., Grubinska, B., and Wiggins, R. C. 1994. Generation of labeled DNA probes by PCR. Pages 37-42 in: PCR Technology: Current Innovations. H. G. Grffin and A. M. Griffin, eds. CRC Press, Boca Raton, FL.

Kulmburg, P., Mathieu, M., Dowzer, C., Kelly, J., and Felenbok, B. 1993. Specific binding sites in the AlcR and AlcA promoters of the ethanol regulon for the CREA repressor mediating carbon catabolite repression in Aspergillus nidulans. Mol. Microbiol. 7:847-857.

Malardier, L., Daboussi, M. J., Julien, J., Roussel, F., Scazzocchio, C., and Brygoo, Y. 1989. Cloning of the nitrate reductase gene (niaD) of Aspergillus nidulans and its use for transformation of Fusarium oxysporum. Gene 78:147-156.

Mann, B. 1962. Role of pectic enzymes in the Fusarium wilt syndrome of tomato. Trans. Br. Mycol. Soc. 45:169-178.

Powell, W. A., and Kistler, H. C. 1990. In vivo rearrangement of foreign DNA by Fusarium oxysporum produces linear self-replicating plasmids. J. Bacteriol. 172:3163-3171.

Punt, P. J., Oliver, R. P., Dingemanse, M. A., Pouwels, P. H., and van den Hondel, C. A. M. 1987. Transformation of Aspergillus based on the hygromycin B resistance marker from Escherichia coli. Gene 56: 117-124.

Raeder, U., and Broda, P. 1985. Rapid preparation of DNA from filamentous fungi. Lett. Appl. Microbiol. 1:17-20.

Reymond-Cotton, P., Fraissinet-Tachet, L., and Fèvre, M. 1996. Expression of the Sclerotinia sclerotiorum polygalacturonase pg1 gene: Possible involvement of CREA in glucose catabolite repression. Curr. Genet. 30:240-245.

Ried, J. L., and Collmer, A. 1985. Activity stain for rapid characterization of pectic enzymes in isoelectric focusing and sodium dodecyl sulfate-polyacrylamide gels. Appl. Environ. Microbiol. 50:615-622.

Sambrook, J., Fritsch, E. F., and Maniatis, T. A. 1989. Molecular Cloning: A Laboratory Manual. 2nd ed. Cold Spring Harbor Laboratory, Cold Spring Harbor, NY.

Schippers, B., and van Eck, W. H. 1981. Formation and survival of chlamidospores in Fusarium. Pages 250-260 in: Fusarium: Diseases, Biology and Taxonomy. P. E. Nelson, T. A. Toussoun, and R .J. Cook, eds. Pennsylvania State University Press, University Park.

Scott-Craig, J. S., Panaccione, D., Cervone, F., and Walton, J. D. 1990. Endopolygalacturonase is not required for pathogenicity of Cochliobolus carbonum on maize. Plant Cell 2:1191-1200.

Tenberge, K. B., Homann, V., Oeser, B., and Tudzynski, P. 1996. Structure and expression of two polygalacturonase genes of Claviceps purpurea oriented in tandem and cytological evidence for pectinolytic enzyme activity during infection of rye. Phytopathology 86:10841097.

von Heijne, G. 1986. A new method for predicting signal sequence cleavage sites. Nucleic Acids Res. 14:4683-4690.

Walton, J. D. 1994. Deconstructing the cell wall. Plant Physiol. 104: $1113-1118$ 